\title{
C-Reactive Protein in Cardiovascular Disease
}

\author{
Iddah, M. Ali $^{1 *}$, Benard O. Wesonga ${ }^{2}$ \\ ${ }^{1}$ Department of Medical Microbiology and Parasitology, School of Medicine, Masinde Muliro University of Science and Technology, \\ P.O. Box 190-50100, Kakamega, Kenya \\ ${ }^{2}$ Departments of Community Health and Behavoural Sciences, School of Medicine, Masinde Muliro University of Science and \\ Technology P.O. Box 190-50100, Kakamega, Kenya

\begin{abstract}
Article History
Received: 12.11 .2020

Accepted: 24.11.2020

Published: 09.12.2020

Journal homepage: HAART (Highly active anti retro viral therapy) has considerably improved. However considerable work is still needed to educate the population about primary and secondary prevention modalities. Moreover regular monitoring of immune response with patients on HAART with conventional biomarkers is still a problem in low resource settings which needs to be addressed. We aim to review hsCRP as a potential biomarker in this regard. Keywords: Highly active anti retro viral therapy HAART, C-Reactive Protein, Cardiovascular Disease, CRP.
\end{abstract} \\ https://www.easpublisher.com \\ Abstract: As we herald into the 21st century, the quality of life and the repertoire of
}

Quick Response Code

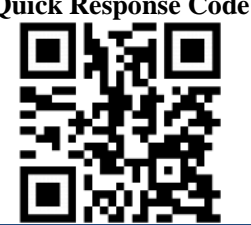

Copyright (C) 2020 The Author(s): This is an open-access article distributed under the terms of the Creative Commons Attribution 4.0 International License (CC BY-NC 4.0) which permits unrestricted use, distribution, and reproduction in any medium for non-commercial use provided the original author and source are credited.

\section{INTRODUCTION}

Over the past two decades with the advent of HAART (Highly active anti-retroviral therapy), there is a substantial increase in the life span of HIV patients. Hence the focus has now shifted to managing long term complications of HIV infection, predicting disease progression and improving quality of life of HIV patients, especially in developed countries. On the other hand, in developing countries the ever growing incidence of HIV infection has placed a huge burden on their frail economy. Hence there is a growing need for simplifying HIV treatment protocols and for having cheaper alternatives for monitoring disease activity.

High-sensitivity C-reactive protein (hsCRP) has been touted as a potential solution for both these problems. First, hsCRP is considered to be a potential biomarker for predicting long term disease progression and CVD risk, which is one of the major long term complications in HIV patients. Secondly, it is also considered to be a marker for predicting mortality and as a tool for routine monitoring of disease activity with a potential to replace traditional costlier measures like CD4 count and HIV RNA load etc. This review highlights the results of some promising studies conducted till now in this regard.

\section{CRP - An Inlammatory Biomarker}

C-Reactive protein was first identified by Tillett and Francis in 1930 as a substance in the serum of patients with acute inflammation that reacted with the C-polysaccharide of pneumococcus (hence the name) [1]. Later it was found to be a acute phase reactant with a pentameric structure that remain stable for a sufficiently long time, allowing measurements of thousands of stored serum samples [2]. Most CRP is produced from liver apart from vascular endothelium in response to IL-6 produced from macrophages and adipocytes [3, 4]. Traditional CRP assays have been available for decades but these assays are not sensitive at lower concentration of CRP. But with the advent of newer highly sensitive CRP (hsCRP) assays like ELISA, Immunoturbimetric assay, laser nephalometry etc, it is now possible to detect low range differences in CRP levels and has thus become the main focus of research in vascular inflammation.

\section{hsCRP - Marker Of HIV Disease Progression}

Immune activation has been demonstrated to be a significant contributor to HIV disease progression in multiple studies [5-8]. It was observed that this immune activation was associated with increased levels of bacterial components in blood, which was hypothesized to be due to increased microbial translocation from the Gastro-Intestinal (GI) tract of patients and this microbial translocation was 
hypothesized to contribute for HIV disease progression $[9,10]$. Naturally CRP being an acute phase reactant should increase in patients with HIV disease progression if it is associated with microbial translocation and immune activation as hypothesized in these studies [3, 11-13]. This theory was tested by Andrew et al. in Rakai, Uganda [14] in a longitudinal study, where study population was divided into three populations - Long term non-progressor (LNTP i.e., CD4>600 cells $/ \mu 1$ at $>7$ yrs after seroconversion), Standard progressors (SP i.e., death $>5$ but $<9$ yrs after seroconversion) and rapid progressors (RP i.e., death within 4 yrs after seroconversion). The results of this study concluded that there is a significant association of immune activation, as measured by hsCRP levels with HIV disease progression. However, there was no association of hsCRP levels with markers of microbial translocation like lipopolysaccharide-LPS, endotoxin antibody, LPS-binding protein, soluble CD14, thus disproving the hypothesis that microbial translocation is responsible for immune activation associated with HIV disease progression.

\section{Predictor of HIV Related Outcomes}

Higher hsCRP concentrations have been associated with lower CD4 counts and higher HIV viral RNA load among HIV infected individuals [11]. Results from studies evaluating serum hsCRP as a predictor of HIV related mortality yielded mixed results in resource rich settings. Some studies have reported significant associations between increased hsCRP concentration and faster progression to AIDS and greater risk of mortality but did not use clinically established hsCRP cut-off concentration [11, 13, 15]. Some studies found that a clinically elevated hsCRP concentration was associated with significantly reduced mortality risk [16-18]. Paul drain et al. [19] studied hsCRP levels as a marker of maternal disease progression and child mortality in HIV infected mothers from Tanzania. They found out that high hsCRP concentration was better than either low CD4 count $<200 / \mu \mathrm{l}$ and high viral load $\geq 50,000 \mathrm{copies} / \mathrm{ml}$ for predicting maternal disease progression to AIDS. While hsCRP was not better than CD4 count or viral load in predicting maternal mortality outcomes, they remained a very strong and almost comparable predictor. These finding could be supported by the fact that the HIV patients are prone to opportunistic infection (mostly bacterial). The more the infection, the higher will be their CRP level (as it is an acute phase reactant) and higher is their chances of progression to AIDS. The exception to this argument is that when the CD4 count is very low $(<50)$, it was found that the ability to mount a CRP response to Pneomo- cystic carina Pneumonia (PCP) infection is substantially small [18], while there is significant risk of death despite low levels of hsCRP. Second finding that supports the results of this study is that HIV infection is regarded as a generalized inflammatory state that leads to depletion of vitamins and minerals. Deficiencies of vitamins and minerals have been found to be associated with disease progression and mortality among HIV positive patients [20-23]. Also high hsCRP levels were found to be associated with depleted stores of vitamins and minerals among HIV positive [21, 24] and HIV negative [25-28] adults. This indirectly supports the finding that high hsCRP was associated with greater risk of disease progression and mortality.

In addition, Drain et al. also found that high maternal hsCRP was a better marker than viral load in predicting child mortality less than 2 years of age independent of maternal anthropometric measurements, CD4 count, viral RNA load and breast feeding status at the time of hsCRP measurement. This finding was supported by the fact that high maternal hsCRP may be a marker or cause of disease progression in mother, leading to deficient transfer of passive immunity and nutrients to the child making them prone for infection and subsequent higher risk of mortality $[29,30]$. Poor caring practice due to maternal morbidity or death is also a plausible social explanation for poor child outcomes.

\section{hsCRP as a CVD Risk Predictor in HIV Patients}

HIV infected patients are at higher risk of cardiovascular disease (CVD) than uninfected general population $[31,32]$. This is believed to be due to modification of traditional CVD risk factors [31] and pathogenic pathways of atherosclerosis and CVD [31, 33-38] by HIV infection and cART (combination ART). A study by De Luca et al. found a significant association between elevated hsCRP and CVD risk in HIV positive patients receiving cART. There was 8 fold increase in CVD risk in patients with CRP levels $>3.3$ $\mathrm{mg} / \mathrm{L}$ than those with $<0.9 \mathrm{mg} / \mathrm{L}$. A key finding of this study was that the effect of hsCRP on CVD risk was independent of traditional risk factors (like deranged lipid profile) and potential confounders Like Body Mass Index (BMI, renal function, and use of statins). There was a strong but crude association of this marker with short term CVD risk but it was found to be a useful marker to predict the medium to long term risk of experiencing CVD events. This study also identified 3.3 $\mathrm{mg} / \mathrm{L}$ as a potential threshold associated with significant risk of CVD in HIV infected patients [39, 40]. However in disagreement with these findings Ford et al. showed no association between hsCRP and CVD events in treated HIV patients [38]. While hsCRP was found to be elevated in patients with low risk of CVD events in a study by Boger et al. [41].

\section{Change In hsCRP Levels with ART}

Several studies have suggested a positive association between ART and CVD risk [31, 42, 43]. Theoretically hsCRP being a marker of CVD risk should increase with ART. On the contrary, there is also evidence that ART may improve endothelial function and protect against atherosclerosis thereby reducing CVD risk [44, 45]. Considering these associations, the 
impact of ARV therapy on hsCRP levels is of significant interest. In Aids Clinical Trials Group (ACTG) 5056s, with the introduction of indinavir, hsCRP levels remained stable or decreased slightly over an average of 42 months [46]. A similar slight decline was seen in the HEAT study over 96 weeks following initiation of lopinavir / ritonavir [47]. Both these findings were noted only in men. In a study by Shikuma et al. [48] a durably suppressive therapy with efavirenz did not improve hsCRP levels over a 96 week period but was associated with significantly increased levels of CRP in women and slight statistically non-significant increase in men. This study also showed that randomization to abacavir had no significant effect on changes in hsCRP levels.

\section{hsCRP Levels In Hiv/Hcv Coinfection}

Both HIV and Hepatitis-C being a chronic infection, activates immune system and results in pro inflammatory state [49-53]. hsCRP being a marker of immune activation should increase in both the infection. However very few studies are available in this regard. Reingold et al. reported that HIV/HCV co infection was associated with a 50\% lower adjusted hsCRP levels when compared with HIV mono infected men and women. It was proposed that HCV infection decreases hsCRP production from liver [54]. This concept is supported by in vitro studies of expression of $\mathrm{HCV}$ proteins in cultured hepatocytes, which causes inhibition of secretion of other liver proteins like apoB$100[55]$.

\section{CONCLUSION}

From the studies conducted to date it can be safely concluded that hsCRP is an excellent predictor of CVD risk in HIV patients. However additional studies are required to analyze the influence of the addition of this marker to the cardiovascular risk scores before implementing routine measurement of hsCRP and to validate its predictability for non-cardiovascular morbidity in HIV patients.

\section{For a marker of risk to be valid, it must have}

- A plausible biological mechanism

- Applicability to both genders

- Ability to enhance our current risk estimation

- Applicability to populations in various geographic localities

In case of hsCRP, not only all these criteria are met, but the risk factor can also be modified [2]. hsCRP is also a reliable marker of disease progression and a cheaper alternative for routine disease monitoring and predicting HIV related outcomes especially in a resource poor settings. But further studies are required to understand the changes in hsCRP levels after HAART therapy and in HIV/HCV co infection, as the currently available data are either contradictory or insufficient.

\section{REFERENCES}

1. Tillett, W. S., \& Francis Jr, T. (1930). Serological reactions in pneumonia with a non-protein somatic fraction of pneumococcus. The Journal of experimental medicine, 52(4), 561.

2. Deron, S. J. (2007). C-reactive protein: An inflammatory biomarker in clinical practice. The Journal of Lancaster General Hospital, 2, 63-68.

3. Pepys, M. B., \& Hirschfield, G. M. (2003). C-reactive protein: a critical update. The Journal of clinical investigation, 111(12), 1805-1812.

4. Lau, D. C., Dhillon, B., Yan, H., Szmitko, P. E., \& Verma, S. (2005). Adipokines: molecular links between obesity and atheroslcerosis. American Journal of Physiology-Heart and Circulatory Physiology, 288(5), H2031-H2041.

5. Bentwich, Z., Kalinkovich, A., \& Weisman, Z. (1995). Immune activation is a dominant factor in the pathogenesis of African AIDS. Immunology today, 16(4), 187-191.

6. Rizzardini, G., Piconi, S., Ruzzante, S., Fusi, M. L., Lukwiya, M., Declich, S., \& Clerici, M. (1996). Immunological activation markers in the serum of African and European HIV-seropositive and seronegative individuals. Aids, 10(13), 1535-1542.

7. McCune, J. M. (2001). The dynamics of CD4+ T-cell depletion in HIV disease. Nature, 410(6831), 974979.

8. Douek, D. C. (2003). Disrupting T-cell homeostasis: how HIV-1 infection causes disease. AIDS reviews, 5(3), 172-177.

9. Brenchley, J. M., Price, D. A., Schacker, T. W., Asher, T. E., Silvestri, G., Rao, S., \& Blazar, B. R. (2006). Microbial translocation is a cause of systemic immune activation in chronic HIV infection. Nature medicine, 12(12), 1365-1371.

10. Brenchley, J. M., Price, D. A., \& Douek, D. C. (2006). HIV disease: fallout from a mucosal catastrophe?. Nature immunology, 7(3), 235-239.

11. Lau, B., Sharrett, A. R., Kingsley, L. A., Post, W., Palella, F. J., Visscher, B., \& Gange, S. J. (2006). Creactive protein is a marker for human immunodeficiency virus disease progression. Archives of internal medicine, 166(1), 64-70.

12. Zulu, I., Hassan, G., Njobvu, L., Dhaliwal, W., Sianongo, S., \& Kelly, P. (2008). Cytokine activation is predictive of mortality in Zambian patients with AIDS-related diarrhoea. BMC infectious diseases, 8(1), 156.

13. Melchior, J. C., Niyongabo, T., Henzel, D., DurackBown, I., Henri, S. C., \& Boulier, A. (1999). Malnutrition and wasting, immunodepression, and chronic inflammation as independent predictors of survival in HIV-infected patients. Nutrition, 15(1112), 865-869.

14. Redd, A. D., Eaton, K. P., Kong, X., Laeyendecker, O., Lutalo, T., Wawer, M. J., ... \& Quinnon, T. C. (2010). C-reactive protein levels increase during HIV1 disease progression in Rakai, Uganda despite the 
absence of microbial translocation. Journal of acquired immune deficiency syndromes (1999), 54(5), 556.

15. Feldman, J. G., Goldwasser, P., Holman, S., DeHovitz, J., \& Minkoff, H. (2003). C-reactive protein is an independent predictor of mortality in women with HIV-1 infection. JAIDS Journal of Acquired Immune Deficiency Syndromes, 32(2), 210214.

16. Sandström, S. G. E. (1999). C-reactive protein levels in HIV complicated by opportunistic infections and infections with common bacterial pathogens. Scandinavian journal of infectious diseases, 31(3), 229-234.

17. Triant, V. A., Meigs, J. B., \& Grinspoon, S. K. (2009). Association of C-reactive protein and HIV infection with acute myocardial infarction. Journal of acquired immune deficiency syndromes (1999), 51(3), 268.

18. Hsue, P. Y., Deeks, S. G., \& Hunt, P. W. (2012). Immunologic basis of cardiovascular disease in HIVinfected adults. Journal of Infectious Diseases, 205(suppl_3), S375-S382.

19. Drain, P. K., Kupka, R., Msamanga, G. I., Urassa, W., Mugusi, F., \& Fawzi, W. W. (2007). C-reactive protein independently predicts HIV-related outcomes among women and children in a resource-poor setting. AIDS (London, England), 21(15), 2067.

20. Storgaard, M., Laursen, A. L., \& Andersen, P. L. (1993). The C-reactive protein responses in HIVinfected patients with pneumonia. Scandinavian journal of infectious diseases, 25(3), 305-309.

21. Look, M. P., Rockstroh, J. K., Rao, G. S., Kreuzer, K. A., Spengler, U., \& Sauerbruch, T. (1997). Serum selenium versus lymphocyte subsets and markers of disease progression and inflammatory response in human immunodeficiency virus-1 infection. Biological Trace Element Research, 56(1), 31-41.

22. Semba, R. D., \& Tang, A. M. (1999). Micronutrients and the pathogenesis of human immunodeficiency virus infection. British Journal of Nutrition, 81(3), 181-189.

23. Kupka, R., \& Fawzi, P. W. (2002). Zinc nutrition and HIV infection. Nutrition reviews, 60(3), 69-79.

24. Baeten, J. M., McClelland, S. R., Richardson, B. A., Bankson, D. D., Lavreys, L., Wener, M. H., ... \& Kreiss, J. K. (2002). Vitamin A deficiency and the acute phase response among HIV-1-infected anduninfected women in Kenya. JAIDS Journal of Acquired Immune Deficiency Syndromes, 31(2), 243249.

25. Ford, E. S., Liu, S., Mannino, D. M., Giles, W. H., \& Smith, S. J. (2003). C-reactive protein concentration and concentrations of blood vitamins, carotenoids, and selenium among United States adults. European journal of clinical nutrition, 57(9), 1157-1163.

26. Maehira, F., Luyo, G. A., Miyagi, I., Oshiro, M., Yamane, N., Kuba, M., \& Nakazato, Y. (2002). Alterations of serum selenium concentrations in the acute phase of pathological conditions. Clinica chimica acta, 316(1-2), 137-146.
27. Ghayour-Mobarhan, M., Taylor, A., New, S. A., Lamb, D. J., \& Ferns, G. A. A. (2005). Determinants of serum copper, zinc and selenium in healthy subjects. Annals of clinical biochemistry, 42(5), 364375.

28. Koyanagi, A., Kuffo, D., Gresely, L., Shenkin, A., \& Cuevas, L. E. (2004). Relationships between serum concentrations of C-reactive protein and micronutrients, in patients with tuberculosis. Annals of Tropical Medicine \& Parasitology, 98(4), 391-399.

29. Pitt J, Henrard D, FitzGerald G, Mofenson L, Lew J, Hillyer G, Mendez H, Cooper E, Hanson C, Rich KC. Human immunodeficiency virus (HIV) type 1 antibodies in perinatal HIV-1 infection: association with human HIV-1 transmission, infection, and disease progression. The Journal of infectious diseases. 2000 Oct 1;182(4):1243-6.

30. Fawzi, W. W., Msamanga, G. I., Wei, R., Spiegelman, D., Antelman, G., Villamor, E., ... \& Hunter, D. (2003). Effect of providing vitamin supplements to human immunodeficiency virus-infected, lactating mothers on the child's morbidity and CD4+ cell counts. Clinical Infectious Diseases, 36(8), 1053 1062.

31. Currier, J. S., Lundgren, J. D., Carr, A., Klein, D., Sabin, C. A., Sax, P. E., ... \& Working Group 2. (2008). Epidemiological evidence for cardiovascular disease in HIV-infected patients and relationship to highly active antiretroviral therapy. Circulation, 118(2), e29-e35.

32. Triant, V. A., Lee, H., Hadigan, C., \& Grinspoon, S. K. (2007). Increased acute myocardial infarction rates and cardiovascular risk factors among patients with human immunodeficiency virus disease. The Journal of Clinical Endocrinology \& Metabolism, 92(7), 2506-2512.

33. Law, M. G., Friis-Møller, N., El-Sadr, W. M., Weber, R., Reiss, P., D'Arminio Monforte, A., \& Calvo, G. (2006). The use of the Framingham equation to predict myocardial infarctions in HIV-infected patients: comparison with observed events in the D: A: D Study. HIV medicine, 7(4), 218-230.

34. Maggi, P., Quirino, T., Ricci, E., De Socio, G. V. L., Gadaleta, A., Ingrassia, F., \& Bonfanti, P. (2009). Cardiovascular risk assessment in antiretroviral-naïve HIV patients. AIDS patient care and STDs, 23(10), 809-813.

35. Teitei, J. M., Shore, A., Read, S. E., \& Schiavone, A. (1989). Immune function of vascular endothelial cells is impaired by HIV. Journal of Infectious Diseases, 160(3), 551-552.

36. Zietz, C., Hotz, B., Stürzl, M., Rauch, E., Penning, R., \& Löhrs, U. (1996). Aortic endothelium in HIV-1 infection: chronic injury, activation, and increased leukocyte adherence. The American journal of pathology, 149(6), 1887.

37. de Gaetano Donati, K., Rabagliati, R., Iacoviello, L., \& Cauda, R. (2004). HIV infection, HAART, and endothelial adhesion molecules: current perspectives. The Lancet infectious diseases, 4(4), 213-222. 
38. de Gaetano Donati, K., Rabagliati, R., Tumbarello, M., Tacconelli, E., Amore, C., Cauda, R., \& Lacoviello, L. (2003). Increased soluble markers of endothelial dysfunction in HIV-positive patients under highly active antiretroviral therapy. Aids, 17(5), 765768.

39. De Luca, A., de Gaetano Donati, K., Colafigli, M., Cozzi-Lepri, A., De Curtis, A., Gori, A., \& Iacoviello, L. (2013). The association of high-sensitivity C reactive protein and other biomarkers with cardiovascular disease in patients treated for HIV: a nested case-control study. BMC infectious diseases, 13(1), 414.

40. Ford, E. S., Greenwald, J. H., Richterman, A. G., Rupert, A., Dutcher, L., Badralmaa, Y., \& Sereti, I. (2010). Traditional risk factors and D-dimer predict incident cardiovascular disease events in chronic HIV infection. AIDS (London, England), 24(10), 1509.

41. Boger, M. S., Shintani, A., Redhage, L. A., Mitchell, V., Haas, D. W., Morrow, J. D., \& Hulgan, T. (2009). Highly-sensitive c-reactive protein, body mass index, and serum lipids in HIV-infected persons receiving antiretroviral therapy: a longitudinal study. Journal of acquired immune deficiency syndromes (1999), 52(4), 480.

42. Currier, J. S., Taylor, A., Boyd, F., Dezii, C. M., Kawabata, H., Burtcel, B., \& Hodder, S. (2003). Coronary heart disease in HIV-infected individuals. JAIDS Journal of Acquired Immune Deficiency Syndromes, 33(4), 506-512.

43. Bergersen, B. M. (2006). Cardiovascular risk in patients with HIV infection. Drugs, 66(15), 19711987.

44. Wolf, K., Tsakiris, D. A., Weber, R., Erb, P., Battegay, M., \& Swiss HIV Cohort Study. (2002). Antiretroviral therapy reduces markers of endothelial and coagulation activation in patients infected with human immunodeficiency virus type 1 . The Journal of infectious diseases, 185(4), 456-462.

45. Torriani, F. J., Komarow, L., Parker, R. A., Cotter, B. R., Currier, J. S., Dubé, M. P., ... \& Squires, K. (2008). Endothelial function in human immunodeficiency virus-infected antiretroviral-naive subjects before and after starting potent antiretroviral therapy: The ACTG (AIDS Clinical Trials Group) Study 5152s. Journal of the American College of Cardiology, 52(7), 569-576.

46. Henry, K., Kitch, D., Dube, M., Zackin, R., Parker, R. A., Sprecher, D., ... \& Adult AIDS Clinical Trials Group. (2004). C-Reactive protein levels over time and cardiovascular risk in HIV-infected individuals suppressed on an indinavir-based regimen: AIDS Clinical Trials Group 5056s. Aids, 18(18), 2434-2437.
47. McComsey, G. A., Smith, K. Y., Patel, P., Bellos, N. C., Sloan, L., Lackey, P., ... \& Shaefer, M. S. (2009). Similar reductions in markers of inflammation and endothelial activation after initiation of abacavir/lamivudine (ABC/3TC) or tenofovir/emtricitabine (TDF/FTC) in the HEAT study. $R N A, 4(1)$.

48. Shikuma, C. M., Ribaudo, H. J., Zheng, Y., Gulick, R. M., Meyer III, W. A., Tashima, K. T., ... \& Glesby, and the AIDS Clinical Trials Group A5095 Study Team, M. J. (2011). Change in high-sensitivity creactive protein levels following initiation of efavirenz-based antiretroviral regimens in HIVinfected individuals. AIDS research and human retroviruses, 27(5), 461-468.

49. Fauci, A. S., Pantaleo, G., Stanley, S., \& Weissman, D. (1996). Immunopathogenic mechanisms of HIV infection. Annals of internal medicine, 124(7), 654663.

50. Abbate, I., Romano, M., Longo, R., Cappiello, G., Lo Iacono, O., Di Marco, V., \& Capobianchi, M. R. (2003). Endogenous levels of mRNA for IFNs and IFN-related genes in hepatic biopsies of chronic $\mathrm{HCV}$-infected and non-alcoholic steatohepatitis patients. Journal of medical virology, 70(4), 581-587.

51. Reingold, J. S., Wanke, C., Kotler, D. P., Lewis, C. E., Tracy, R., Heymsfield, S., ... \& Shlipak, M. G. (2008). Association of HIV infection and HIV/HCV coinfection with C-reactive protein levels: the fat redistribution and metabolic change in HIV infection (FRAM) study. Journal of acquired immune deficiency syndromes (1999), 48(2), 142.

52. Stephensen, C. B., Marquis, G. S., Douglas, S. D., \& Wilson, C. M. (2005). Immune activation and oxidative damage in HIV-positive and HIV-negative adolescents. JAIDS Journal of Acquired Immune Deficiency Syndromes, 38(2), 180-190.

53. Khovidhunkit, W., Kim, M. S., Memon, R. A., Shigenaga, J. K., Moser, A. H., Feingold, K. R., \& Grunfeld, C. (2004). Effects of infection and inflammation on lipid and lipoprotein metabolism: mechanisms and consequences to the host. The Journal of Lipid Research, 45(7), 1169-1196.

54. Reingold, J. S., Wanke, C., Kotler, D. P., Lewis, C. E., Tracy, R., Heymsfield, S., ... \& Shlipak, M. G. (2008). Association of HIV infection and HIV/HCV coinfection with C-reactive protein levels: the fat redistribution and metabolic change in HIV infection (FRAM) study. Journal of acquired immune deficiency syndromes (1999), 48(2), 142.

55. Domitrovich, A. M., Felmlee, D. J., \& Siddiqui, A. (2005). Hepatitis C virus nonstructural proteins inhibit apolipoprotein B100 secretion. Journal of Biological Chemistry, 280(48), 39802-39808. 